\title{
ARTICLE
}

\section{Ab Initio RAFT Emulsion Polymerization mediated by Small Cationic RAFT Agents to Form Polymers with Low Molar Mass Dispersity}

Received 00th January 20xx, Accepted 00th January 20xx DOI: $10.1039 / \times 0 \times x 00000 x$

\author{
Sarah J. Stace, ${ }^{a, b}$ Jochen Vanderspikken, ${ }^{b, c}$ Shaun C. Howard, ${ }^{b}$ Guoxin Li, ${ }^{b}$ Benjamin W. Muir, ${ }^{b}$
} Christopher M. Fellows, ${ }^{*, a}$ Daniel J. Keddie*,a,d and Graeme Moad*,b

\section{Introduction}

Since the first reports of reversible addition fragmentation chain transfer (RAFT) polymerization ${ }^{1}$ and, indeed, reversible deactivation radical polymerization (RDRP, otherwise known as living or controlled radical polymerization ${ }^{2}$ ), there has been a strong drive to develop batch $a b$ initio emulsion RDRP based on direct use of low molar mass control agents. ${ }^{3-7}$ This interest can be understood in terms of the importance of emulsion polymerization to industrial polymer production, ${ }^{8}$ for example, diene-polymers. ${ }^{9}$

RAFT emulsion polymerizations commencing with low molar mass thiocarbonylthio RAFT agents were first reported by CSIRO and Rhodia in their initial papers ${ }^{1,10,11}$ and patents ${ }^{12,13}$ on RAFT polymerization. The CSIRO examples ${ }^{11}$ that were successful in providing low dispersity polymers (e.g.,

\footnotetext{
${ }^{a .}$ School of Science and Technology, University of New England, Armidale, NSW 2351, Australia.

b. CSIRO Manufacturing, Bag 10, Clayton South, VIC 3169, Australia

c. Hasselt University, Institute for Materials Research (IMO), Agoralaan 1 - Building D, 3590 Diepenbeek, Belgium.

${ }^{d .}$ School of Biology, Chemistry and Forensic Science, University of Wolverhampton, Wulfruna Street, Wolverhampton West Midlands WV1 $1 L Y$, United Kingdom. † Footnotes relating to the title and/or authors should appear here.

Electronic Supplementary Information (ESI) available: Full experimental details and detains of Chemspeed high throughput experiments with RAFT agents $\mathbf{4}$ and $\mathbf{5}$ See DOI: 10.1039/x0xx00000x
}

$\bigoplus_{\mathrm{m}}<1.2$ ) were starved-feed (also known as semi-batch) emulsion polymerizations. The conditions used were similar to those that had been found successful in forming low dispersity block polymers with macromonomer RAFT agents. ${ }^{14,15}$ The starved-feed protocol was utilized because initial attempts to form low dispersity polymers by ab-initio batch emulsion RAFT polymerization in the presence of more active RAFT agents such as the dithiobenzoates had failed. ${ }^{16}$

Monteiro and co-workers studied RAFT emulsion polymerization in greater depth and found that the direct use of more active RAFT agents (in particular, cumyl dithiobenzoate) in a batch $a b$ initio process was generally unsuccessful and the polymerizations were characterized by substantial retardation or inhibition, poor latex stability and broad or multimodal molar mass distributions. Much of this early work on heterogeneous RAFT polymerization focused on styrene (St) polymerization, ${ }^{17-20}$ although polymerizations of butyl acrylate (BA), ${ }^{21}$ methacrylates ${ }^{17}$ and other monomers were also reported. Luo et al. ${ }^{22}$ proposed an explanation for the lack of success in RAFT emulsion polymerization in terms of "super swelling' caused by the presence of the large concentrations of short oligomers that are formed early in the polymerization and which is characteristic of an efficient RDRP. It was found that the problem could be mitigated, though not fully resolved, though the use of very high concentrations of conventional surfactants and/or by the use of non-ionic surfactants. $^{23}$ 
Several groups reported that less active (low transfer constant) RAFT agents could be used to conduct a successful batch $a b$ initio emulsion polymerization. ${ }^{21,24}$ This avoided the formation of high concentrations of short oligomers at low monomer conversions. However, the level of control achievable was then compromised, in that polymers with low molar mass dispersity were not formed $\left(\theta_{m}\right.$ usually $\left.>2\right)$. In some circumstances, seeded emulsion polymerizations ${ }^{25,26}$ and miniemulsion polymerizations ${ }^{17,20,27}$ using more active RAFT agents to form low dispersity polymers were more successful.

A significant advance came with the development of amphiphilic macroRAFT agents. ${ }^{28,29}$ A recent review has summarized the state of the art for ab initio "surfactant-free" RAFT emulsion polymerization. ${ }^{7}$ The amphiphilic macroRAFT comprises a hydrophilic block, such as poly(acrylic acid), ${ }^{28-33}$ poly( $\mathrm{N}$-acryloylpyrrolidine), ${ }^{34}$ poly(ethylene glycol), ${ }^{35}$ poly(poly(ethylene glycol) methyl ether acrylate-co- $N$ (hydroxyethyl)acrylamide) $^{36}$ or poly(di(ethylene glycol) methyl ether methacrylate-co- $N$-(2-hydroxypropyl)methacrylamideco-poly(ethylene glycol) methyl ether methacrylate), ${ }^{37}$ and a hydrophobic block usually composed of the monomer being polymerized, which can be formed in situ. An issue with this methodology, is that the product is always a block copolymer with the hydrophilic segment of the macroRAFT agent stoichiometrically incorporated into the final product. In some cases, this hydrophilic segment is critically important in directing polymerization-induced self-assembly (PISA), in others it is a defect that is impossible to remove from the polymer product. There are a few reports of the successful use of low molar mass RAFT agents RSC(=S)Z in $a b$ initio RAFT emulsion polymerization of styrene and other monomers. ${ }^{7,38,39}$ These RAFT agents generally comprised carboxylic acid functionality in the R group and suffer from some of the same issues as the amphiphilic RAFT agent approach.

One feature that characterizes the more successful protocol for RAFT emulsion polymerization (starved feed systems, amphiphilic macroRAFT agents, seeded systems, most miniemulsion systems) with more active RAFT agents has been the use of some strategy to localize the RAFT agent preferentially in a colloidally stable particle phase from the early stages of polymerization. In contrast, the low molar mass RAFT agents used in the unsuccessful $a b$ initio experiments have been sufficiently hydrophobic, that if used directly in a batch ab initio process, they would initially be predominantly located in the monomer droplet phase.

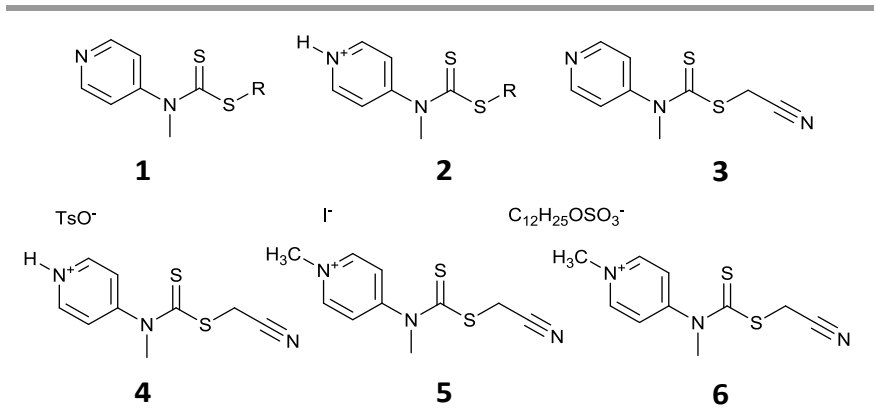

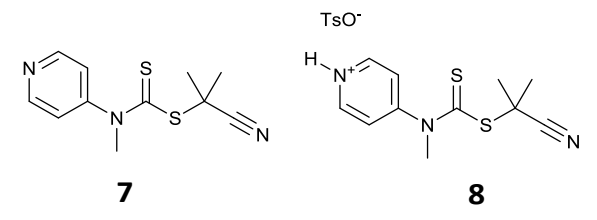

Chart 1. Structures of (pyridin-4-yl)carbamodithioate RAFT agents.

The (pyridin-4-yl)carbamodithioates $\mathbf{1}$ were initially designed for use as switchable RAFT agents that can provide good control over both more and less activated monomers (MAMs and LAMs). ${ }^{40-49}$ In their switched or protonated state, 2, they allow the synthesis of low $\bigoplus_{m}$ poly(MAM)s, e.g., polystyrene with $\mathbf{4}$, and in their unswitched or neutral state, $\mathbf{1}$, facile polymerization of LAMs to give low $\bigoplus_{m}$ poly(LAM)s, e.g., poly $(\mathrm{VAc})$ with 3 . These RAFT agents also enable the preparation of low $\Xi_{m}$ poly(MAM)-block-poly(LAM)s by sequential monomer addition.

The initial motivation for the present work was to establish whether such switchable RAFT agents could be successfully used in heterogeneous polymerization. We had previously shown (and confirmed in this work) ${ }^{\ddagger}$ that, in their switched protonated form 2, these RAFT agents are predominantly located in the aqueous, continuous, phase. The previous work demonstrated the utility of 4 as a RAFT agent in homogeneous aqueous solution. ${ }^{47}$

\section{Results and Discussion}

\section{Use of the Protonated RAFT agent (2) in Styrene Polymerization}

Our initial findings for $a b$ initio RAFT emulsion polymerization of styrene with $\mathbf{4}$ are summarized in Table 1. Further detail is provided in the ESI. In these experiments, the RAFT agent 3 was converted to the protonated form 4 in situ by addition of one equivalent of 4-toluenesulfonic acid ( $\mathrm{TsOH})$.

\begin{tabular}{cccccc}
\hline Table 1. RAFT emulsion polymerization of styrene. \\
\hline $\begin{array}{c}\text { RAFT } \\
\text { agent }\end{array}$ & $\begin{array}{c}\text { Time } \\
(\mathrm{h})\end{array}$ & $\begin{array}{c}\text { conv. } \\
(\%)\end{array}$ & $\begin{array}{c}M_{\mathrm{n}}^{\text {th } a} \\
\left(\mathrm{~g} \mathrm{~mol}^{-1}\right)\end{array}$ & $\begin{array}{c}M_{\mathrm{n}} \\
\left(\mathrm{g} \mathrm{mol}^{-1}\right)\end{array}$ & $\bigoplus_{\mathrm{m}}$ \\
\hline $\mathbf{4}^{b}$ & 5 & 73 & 20300 & 18950 & 1.21 \\
$\mathbf{4}^{c}$ & 25 & 84 & 23450 & 30300 & 1.36 \\
$\mathbf{4}^{d}$ & 24 & 91 & 25300 & 25400 & 1.32 \\
\hline
\end{tabular}

${ }^{a}$ see ESI, where estimation of the fraction of living chains and initiator efficiencies are also discussed. ${ }^{b}$ with $2.7 \mathrm{M}$ styrene, $0.0102 \mathrm{M}$ RAFT agent, $0.0102 \mathrm{M} \mathrm{TsOH}, 0.0012 \mathrm{M} \mathrm{Na}_{2} \mathrm{~S}_{2} \mathrm{O}_{8}$ and $0.015 \mathrm{M} \mathrm{SDS}$ in $10 \mathrm{~mL} \mathrm{H} 2 \mathrm{O} .^{c}$ with $2.7 \mathrm{M}$ styrene, $0.0102 \mathrm{M}$ RAFT agent, $0.0102 \mathrm{M} \mathrm{TsOH}, 0.0102 \mathrm{M} \mathrm{Na}_{2} \mathrm{~S}_{2} \mathrm{O}_{8}$ and $0.015 \mathrm{M}$ SDS in $10 \mathrm{~mL} \mathrm{H2O}{ }^{d}$ with $2.7 \mathrm{M}$ styrene, $0.0102 \mathrm{M}$ RAFT agent, $0.0102 \mathrm{M} \mathrm{TsOH}$, $0.0102 \mathrm{M} \mathrm{ACPA}$ and $0.015 \mathrm{M}$ SDS in $10 \mathrm{~mL} \mathrm{H} 2 \mathrm{O}$.

The conditions chosen for $a b$ initio RAFT emulsion polymerization with $\mathbf{4}$ were based on those used by Monteiro et $a l^{50}$ for RAFT emulsion polymerization of styrene with xanthate RAFT agents. The procedure involved combining all ingredients other than initiator in a Schenk flask and stirring for $24 \mathrm{~h}$ to form an emulsion. In our experiments, the unbuffered medium as prepared was acidic $(\mathrm{pH} \sim 4)$. No buffer was used to help ensure the RAFT agent was maintained in a protonated state and NaPS or KPS were used as initiators. 
However, persulfate salts are hydrolytically unstable under acidic conditions ${ }^{51,52}$ and may oxidise RAFT agents in homogeneous aqueous solution. To minimize the impact of these issues, the initiator was added after the emulsification steps, immediately before polymerization.

Initial experiments (e.g., Table 1, entry 1) featured a relatively small monomodal particle size by DLS $\left(D^{*} \sim 70 \mathrm{~nm}\right.$ after dilution and dialysis) and a relatively rapid rate of polymerization. $M_{\mathrm{n}}$ values were slightly lower than that anticipated on the basis of the RAFT agent concentration alone, which is consistent with the formation of initiatorderived chains.

Subsequent experiments (e.g., Table 1, entry 2), showed a significantly slower rate of polymerization and a broader particle size distribution. While relatively low molar mass dispersities $\left(\Theta_{\mathrm{m}}\right)$ were still achieved in these experiments (best case was $\bigoplus_{\mathrm{m}}<1.26$ for $M_{\mathrm{n}} \sim 20000$ ), and it was observed that $M_{\mathrm{n}}$ did increase with conversion in a linear fashion (See ESI), the conversion, $M_{\mathrm{n}}$ and $\Xi_{\mathrm{m}}$ were variable and showed no direct correlation with polymerization time. Usually $M_{\mathrm{n}}$ was significantly higher than that expected on the basis of the RAFT agent concentration (e.g., Table 1, entry 2). This was attributed to consumption of the RAFT agent and initiator in side reactions, which include oxidation of the RAFT agent by persulfate. This side reaction is likely to be more significant under our conditions, than in RAFT emulsion polymerizations that use hydrophobic RAFT agents, because our RAFT agent (4) is predominantly in the aqueous phase.

We therefore turned to 4,4'-azobis(4-cyanopentanoic acid) (ACPA) as initiator. With this initiator, the expected dependence of $M_{n}$ on monomer conversion and RAFT agent concentration was achieved (e.g., Table 1, entry 3, and SI) and the molar mass distributions observed were monomodal and relatively narrow (e.g., Figure 1 ).

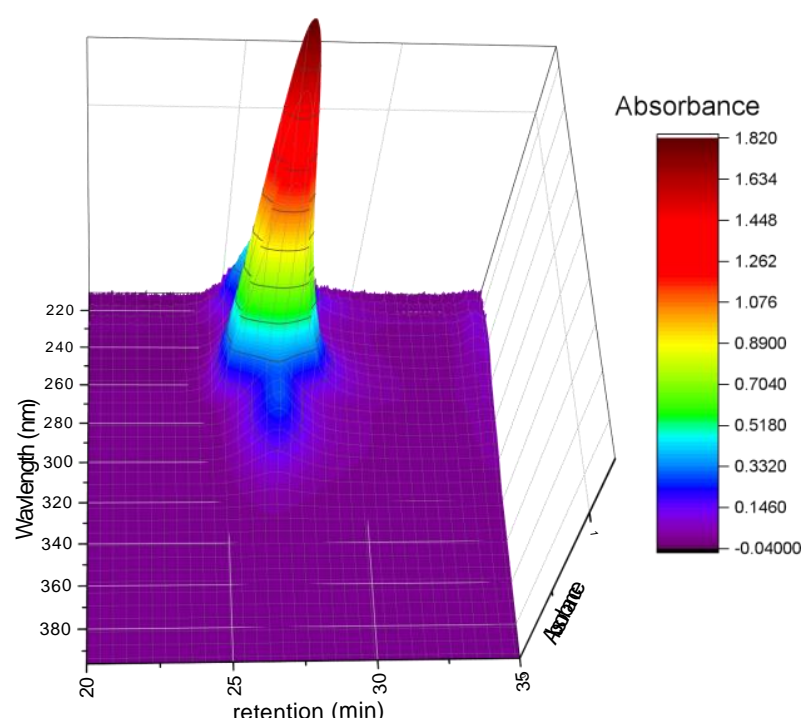

Figure 1. 3D plot of diode array (210-395 nm) data for GPC trace showing monomodal molar mass distribution observed for $a b$ initio emulsion polymerizations of styrene using the protonated RAFT agent 3 (Table 1, entry 3 ). The UV spectrum is consistent with the presence of end group 1 suggesting that deprotonation occurs on passage though the GPC column.
The longer wavelength absorption evident in Figure 1 is consistent with the retention of the (pyridin-4yl)carbamodithioate chromophore. The high initiator concentration compensates for the very low initiator efficiency of $A C P A^{53,54}$ in emulsion polymerization and does not result in a large number of additional initiator-derived chains.

The effects of experimental variables on RAFT emulsion polymerization with the protonated RAFT agent were further explored with use of a high throughput synthesis platform. With the reactor configuration used, stirring of the polymerization mixtures is not possible. A variety of vortexing protocols were thus examined in order to emulsify and obtain latex stability. The most successful strategy for providing a stable latex involved vortexing the reactor vials at high intensity $(800 \mathrm{rpm})$ and lower intensity $(600 \mathrm{rpm})$ for cycles of 10 seconds and 13 minutes, respectively, both during emulsification and the period of polymerization (continuous high intensity vortexing was not practicable). With this protocol in place 48 simultaneous experiments were conducted to systematically explore parameter space. The reference conditions were similar to those used in the Schlenk flask experiments (Table 1 ) with $2.7 \mathrm{M}$ styrene, $0.0102 \mathrm{M}$ RAFT agent 4, $0.0102 \mathrm{M} \mathrm{TsOH}, 0.0102 \mathrm{M}$ ACPA and $0.015 \mathrm{M}$ sodium dodecyl sulfate (SDS). Dispersities obtained in the high throughput experiments were slightly higher than in the Schlenk flask experiments. The results are detailed in the Figure 2 and the ESI. The following features are notable:

- Surfactant concentrations $0.01 \mathrm{M}<[\mathrm{SDS}]<0.02 \mathrm{M}$ appeared optimal. The finding of an optimal SDS concentration is most likely indicative of the occurrence particle aggregation for higher SDS concentrations. Dynamic light scattering (DLS) indicates larger particle size and a broader particle size distribution for higher [SDS]. Higher SDS may also solubilize the RAFT agent in the particle phase. A lower molar mass may indicate a higher initiator efficiency for 0.017 M SDS.

- The outcome of the polymerizations with 3 (or 4) was not substantially affected by the amount of $\mathrm{TsOH} 0.006 \mathrm{M}<$ $[\mathrm{TsOH}]<0.012 \mathrm{M}$. This may suggest that protonationdeprotonation equilibrium is rapid with respect to RAFT under the conditions. Previous work ${ }^{47}$ indicated a necessity to use at least stoichiometric acid to achieve the lowest $\theta_{\mathrm{m}}$ for the case of RAFT polymerization of $\mathrm{N}, \mathrm{N}$-dimethylacrylamide with $\mathbf{3}$ in aqueous solution.

- Initiator concentrations $0.005 \mathrm{M}<[\mathrm{ACPA}]<0.020 \mathrm{M}$ gave similar results. Significantly reduced conversions were seen for lower concentrations $(<0.005 \mathrm{M})$ and higher dispersities were observed for higher concentrations $(>0.020 \mathrm{M}$ ) outside of this range.

- Styrene and RAFT agent were varied independently. Although there is significant scatter, the expected dependence of molar mass on [styrene] and [RAFT] is observed. Good control is observed over the range examined with [styrene]:[RAFT] = 100:1-400:1. Molar mass values are consistent with a high degree of livingness and initiator efficiencies for ACPA of $20 \%$ (see ESI). 


\section{ARTICLE}

(a)

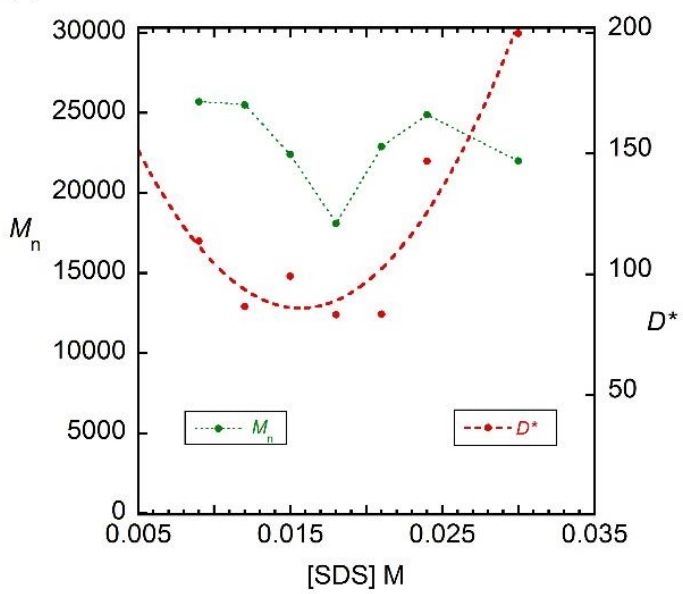

(c)

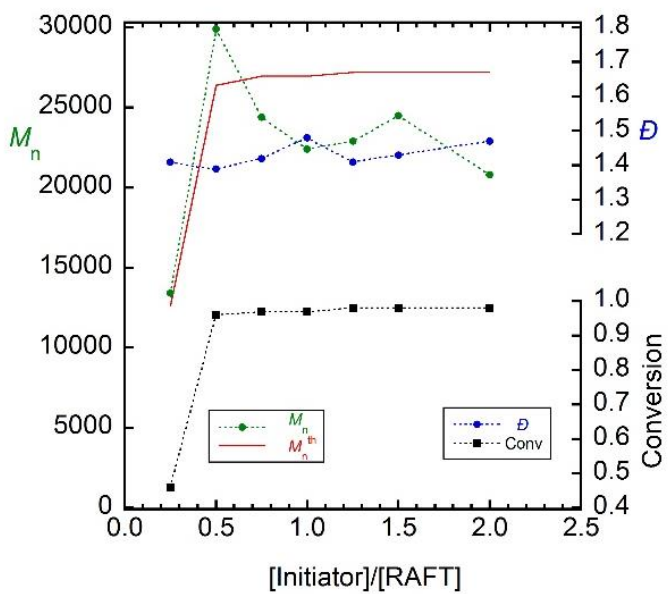

(b)

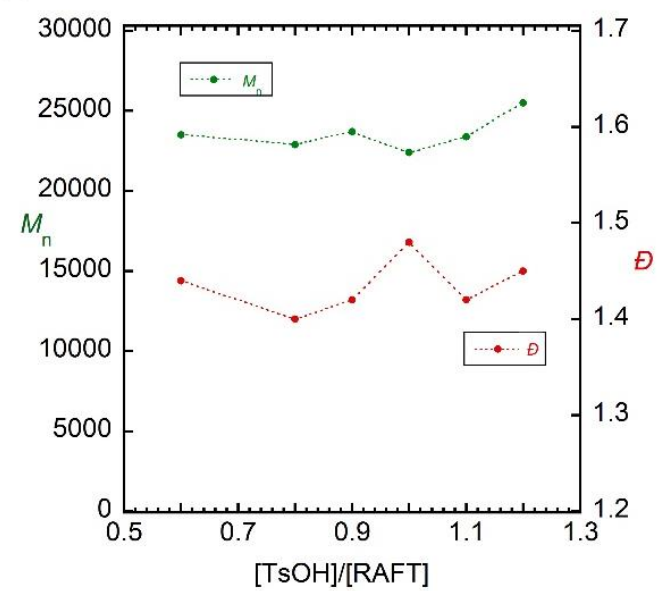

(d)

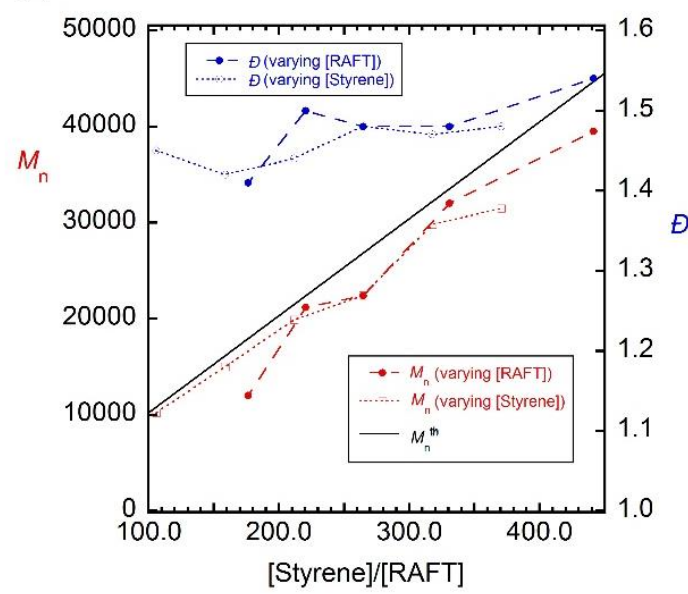

Figure 2. Results of high throughput experiments showing (a) the effect of surfactant (SDS) concentration on $M_{\mathrm{n}}$ and particle size $D^{*}$, (b) the effect of acid (TsOH) concentration on $\mathrm{M}_{\mathrm{n}}$ and $\Theta_{\mathrm{m}}$, (c) the effect of initiator concentration on $M_{n}, \Theta_{\mathrm{m}}$ and monomer conversion and (d) the effect of [RAF]/[Styrene] on $M_{\mathrm{n}}$ and $\Theta_{\mathrm{m}}$ for varying [RAFT] or [Styrene]. The reference experiment used 2.7 M styrene, $0.0102 \mathrm{M}$ RAFT agent 4, $0.0102 \mathrm{M} \mathrm{TsOH}, 0.0102 \mathrm{M}$ ACPA and 0.015 M SDS. All data are provided in the ESI.

Relatively poor control over particle size distributions was evident under the various conditions employed whether in the Schlenk flask experiments or under high throughput conditions. Particle sizes were determined by DLS both immediately upon quenching the polymerization and after dialysis. The particle size distribution of the latex immediately, or within a few weeks after quenching, irrespective of RAFT agent and other conditions explored, appeared trimodal, comprising a peak around 5-10 nm most likely from polymer micelles and/or single chains, small particles (30-70 $\mathrm{nm}$ in size), and some very large particles assumed to be aggregates (>1000 nm), with the smaller $30-70$ $\mathrm{nm}$ particles dominating the intensity size distribution. It is recognized that DLS, particularly when obtained for relatively concentrated samples, is not quantitative. The particle size distribution after significant dilution or dialysis showed mainly larger particles around $200-500 \mathrm{~nm}$ in size. CryoTEM images obtained for selected samples showed spherical particles with sizes consistent with DLS (see ESI).

The faster polymerization rate and slightly better control obtained in the initial Schlenk flask experiments are attributed to compartmentalization effects associated with smaller particles sizes and narrower particle size distributions. Rates of polymerization are higher in a compartmentalized system 
than in a corresponding homogeneous bulk or solution polymerization due to the segregation of propagating radicals and a consequent reduced rate of termination. ${ }^{27,31,55}$

It is not clear what differences in polymerization conditions are responsible for the different outcome but it may relate to use of different polymerization vessels. Further exploration of polymerization conditions with the present RAFT agents is planned to explore these effects.

We believe that the mechanism of particle formation with the pyridyl RAFT agents may be analogous to that proposed for hydrophilic or amphiphilic RAFT agents. In the early stages of polymerization, the water soluble RAFT agent is converted to amphiphilic Z-mers.. These may enter into monomer-swollen SDS micelles or may aggregate to form micelles.

\section{Use of Methyl-Quaternized RAFT agents in Styrene Polymerization}

It was thought that use of a methyl-quaternized RAFT agent would enable polymerization at neutral to slightly alkaline $\mathrm{pH}$ more typical of those used in most conventional emulsion polymerization experiments using SDS as a surfactant and more consistent with the use of persulfate initiation. The RAFT agent 5 was readily prepared ( $89 \%$ yield, see ESI) by treating an acetone solution of $\mathbf{3}$ with 3 equivalents of methyl iodide at ambient temperature.

Emulsion polymerization with the methyl iodidequaternized RAFT agent $\mathbf{5}$ gave a low dispersity polymer with the anticipated $M_{\mathrm{n}}$ but the molar mass distributions were distinctly bimodal (Table 2, entry 1, and ESI) with the larger, higher molar mass component, comprising dead chains (no RAFT chain-ends). A series of high throughput experiments analogous to those performed with $\mathbf{4}$ was performed to look into the effects of polymerization conditions (see ESI), However, all experiments gave bimodal or more complex multimodal distributions and conditions for forming a monomodal, low $\bigoplus_{m}$, product were not identified.

We speculated that concomitant iodine transfer polymerization might be an issue. To circumvent this or other issues that might be associated with the iodide counterion, the iodide of $\mathbf{5}$ was exchanged to provide the RAFT agent $\mathbf{6}$ with a dodecylsulfate counterion. This involved adding $\mathrm{CH}_{2} \mathrm{Cl}_{2}$ and one equivalent SDS to an aqueous solution of $\mathbf{5}$ and stirring for $24 \mathrm{~h}$ during which time 6 partitioned into the organic phase (yield 56\%, see SI).

With this RAFT agent (6) no additional surfactant (such as SDS) was required to provide a low $\bigoplus_{m}$ polystyrene with a monomodal molar mass distribution (Table 2, entry 2). However, good colloidal stability (absence of coagulum) was only seem with higher [RAFT $]_{0}$.
Table 2. RAFT emulsion polymerization of styrene.

\begin{tabular}{cccccc}
\hline $\begin{array}{c}\text { RAFT } \\
\text { agent }\end{array}$ & $\begin{array}{c}\text { Time } \\
(\mathrm{h})\end{array}$ & $\begin{array}{c}\text { conv. } \\
(\%)\end{array}$ & $\begin{array}{c}M_{\mathrm{n}}^{\text {th } a} \\
\left(\mathrm{~g} \mathrm{~mol}^{-1}\right)\end{array}$ & $\begin{array}{c}M_{\mathrm{n}} \\
\left(\mathrm{g} \mathrm{mol}^{-1}\right)\end{array}$ & $\bigoplus_{\mathrm{m}}$ \\
\hline $\mathbf{5}^{\mathrm{b}}$ & 24 & 94 & 26138 & 23100 & 1.39 \\
$\mathbf{6}^{\mathrm{c}}$ & 24 & 97 & 18408 & 32100 & 1.27 \\
\hline
\end{tabular}

a See ESI. ${ }^{b}$ With $2.7 \mathrm{M}$ styrene, $0.0102 \mathrm{M}$ RAFT agent, $0.0102 \mathrm{M}$ 4toluenesulfonic acid, $0.0102 \mathrm{M} \mathrm{ACPA}$ and $0.015 \mathrm{M} \mathrm{SDS}$ in $10 \mathrm{~mL} \mathrm{H2O}$. ${ }^{c}$ With 2.7 $\mathrm{M}$ styrene, $0.0150 \mathrm{M}$ RAFT agent, $0.0102 \mathrm{M}$ ACPA in $10 \mathrm{~mL} \mathrm{H}_{2} \mathrm{O}$, no additional surfactant.

The RAFT end-groups of polystyrene formed with dodecyl sulfate 6, while being retained under polymerization conditions, as evidenced by the formation of a polymer with low $\bigoplus_{\mathrm{m}}$, appear exceptionally labile in that they did not survive for GPC analysis (Figure 3) and were lost on dialysis of the latex. The higher than anticipated molar mass suggests some loss of RAFT agent and, since dispersities are relatively low, this must occur prior to significant monomer conversion. Ease of end group removal may be seen as an advantage, as end group removal can be problematical for polymers formed by heterogeneous polymerization. ${ }^{56-58}$ However, it is an issue if the end-goal is block copolymer synthesis.

In an effort to establish the qualities of the dodecyl sulfate 6 as a RAFT agent under homogenous solution, bulk thermal polymerization of styrene was carried out at $110{ }^{\circ} \mathrm{C}$ under conditions similar to those used for many other RAFT agents. ${ }^{59}$ Under these conditions we found, 6 provided little control and provided a product that did not contain the RAFT en- group (see ESI). The methyl-quaternized RAFT end-group formed with 6 appears very unstable relative to the protonated endgroup formed with $4 .^{40}$ The lower stability in homogenous solution is attributed to the higher reaction temperature.

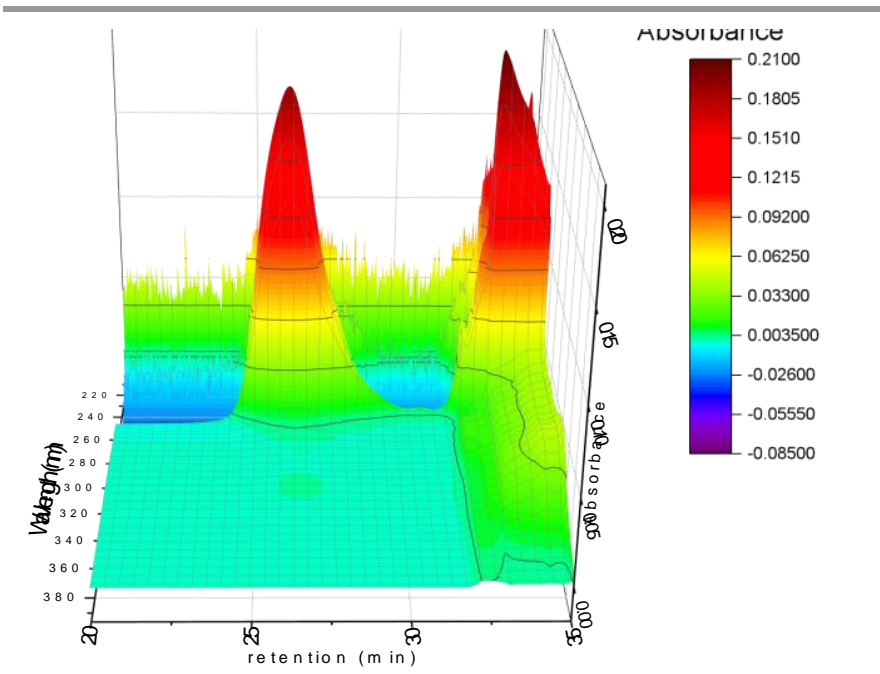

Figure 3. 3D plot of diode array $(210-395 \mathrm{~nm})$ data for GPC traces showing molar mass distribution observed for $a b$ initio emulsion polymerizations of styrene using the quaternized RAFT agent 4. 
<smiles>CC(C)(C)OC(=O)CCC(=O)Oc1ccc(C(=S)SC(C)(C)C#N)cc1</smiles>

9<smiles>CC(C)(C)OCC(C)(C)OC(=O)CCSC(=S)SCc1ccccc1</smiles>

10

Figure 4. Structures of amphiphilic macroRAFT agents $\mathrm{ZC}(=\mathrm{S}) \mathrm{SR}$ in which $\mathrm{Z}$ comprises a hydrophilic poly(ethylene oxide) chain.

Several authors have explored the use of amphiphilic RAFT agents $\mathrm{ZC}(=\mathrm{S}) \mathrm{SR}$ in which $\mathrm{Z}$ contains a hydrophilic polyethylene oxide chain (Figure 4 ) in heterogeneous polymerization. ${ }^{60,61}$ The advantage claimed for these RAFT agents is that the surface active $Z$ groups remain at the surface of the particles formed and are readily removed or modified. A similar situation may pertain in the case of our RAFT agents. The use of lower concentrations of ACPA or other, more efficient, initiators remains to be explored.

The explanation postulated for the effectiveness of $\mathbf{4}$ in terms of water solubility of the RAFT agent does not apply in the case of $\mathbf{6}$ since this RAFT agent shows poor water solubility and partitions in strongly in favour of toluene or methylene chloride in solubility tests. Nonetheless we expect the RAFT agent to be highly surface active. We expect that the mechanism of action for $\mathbf{6}$ is similar to that described for other amphiphilic RAFT agents (vide infra).

Use of RAFT agents 3, 4 and 8 in Emulsion Polymerization of Other Monomers

One-off experiments were conducted with other monomers to further explore the scope of the process. These experiments were conducted under similar conditions to the initial experiments with styrene (e.g., Table 1, entry 1 ). It was important to choose the RAFT agent for the monomers being polymerized. It is established that to achieve low $\emptyset$ in RAFT polymerization, $\mathrm{R}$ must be a good homolytic leaving group with respect to the propagating species. For experiments in homogeneous solution $\mathbf{1}$ with $\mathrm{R}=$ cyanomethyl is appropriate for monosubstituted monomers such as styrene, butyl acrylate, vinyl acetate or vinyl benzoate. Thus $\mathbf{3}$ or $\mathbf{4}$ was used in experiments with LAMs (VAc and VBz) and MAMs (styrene and $\mathrm{BA}$ ), respectively. For 1,1-disubsituted monomers such as methyl methacrylate (MMA) or butyl methacrylate (BMA), 1 with $\mathrm{R}=2$ cyano-2-propyl provides good control. Thus RAFT agent 8 was used in RAFT polymerization of MAMs, BMA and MMA.

As shown in Table 3, the $a b$ initio emulsion polymerization of BA and BMA with $\mathbf{4}$ or $\mathbf{8}$, respectively, provided a stable latex, anticipated $M_{\mathrm{n}}$ and relatively low $\oplus$. Similar polymerization of MMA with 8 provided acceptable $M_{n}$ and $\emptyset$. but the product appeared as a transparent yellow gel rather than a latex.
RAFT emulsion polymerization of vinyl esters (and other LAMS) has been seldom reported. ${ }^{62,63}$ Some of the best results are reported by Nomura et al., ${ }^{63}$ who performed emulsion polymerization of VAc with $10 \mathrm{wt} \%$ PVA as stabilizer/surfactant and VA-044 initiator and evaluated a wide range of xanthates and dithiocarbamates in this context. For polymerization of $\mathrm{VAc}$ and $\mathrm{VBz}$, we used the neutral RAFT agent 3 (the protonated macroRAFT agent is very labile). In this case, we do not have the advantage of the RAFT agent being initially located in the aqueous phase. Nonetheless, under our standard conditions, we see good molar mass control and $\Theta$ 1.7 (Table 3).

\begin{tabular}{|c|c|c|c|c|c|c|}
\hline & $\begin{array}{l}\text { RAFT } \\
\text { agent }\end{array}$ & $\begin{array}{c}\text { Time } \\
\text { (h) }\end{array}$ & $\begin{array}{c}\text { conv. } \\
(\%)\end{array}$ & $\begin{array}{c}M_{\mathrm{n}}^{\text {th } b} \\
\left(\mathrm{~g} \mathrm{~mol}^{-1}\right)\end{array}$ & $M_{\mathrm{n}}{ }^{\mathrm{c}}$ & $\theta_{m}$ \\
\hline BA & 4 & 16 & 80 & 24300 & 23900 & 1.29 \\
\hline BMA & 8 & 3 & 95 & 10200 & 10600 & 1.41 \\
\hline $\mathrm{MMA}^{d}$ & 8 & 6 & 84 & 18600 & 16400 & 1.38 \\
\hline$V A c^{e}$ & 3 & 4 & 85 & 16600 & 17500 & 1.71 \\
\hline VBz & 3 & 4 & 56 & 19800 & 18500 & 1.68 \\
\hline
\end{tabular}

a Experiments with $2.7 \mathrm{M}$ monomer, $0.0102 \mathrm{M}$ RAFT agent, $0.0102 \mathrm{M}$ 4toluenesulfonic acid, $0.0012 \mathrm{M} \mathrm{Na}_{2} \mathrm{~S}_{2} \mathrm{O}_{8}$ and $0.012 \mathrm{M} \mathrm{SDS}$ in $10 \mathrm{~mL} \mathrm{H} 2 \mathrm{O}^{b}$ see ESI. ${ }^{c}$ GPC $M_{n}$ in poly (methyl methacrylate) equivalents. ${ }^{d}$ Product PMMA appears as a transparent yellow gel rather than a latex. ${ }^{e}$ Unstable latex, bimodal molar mass distribution with pronounced tail to low molar mass.

\section{Conclusions}

We have found that low molar mass cationic RAFT agents 4, 6 and 8 provide predictable molar mass and low dispersities $\left(\Theta_{\mathrm{m}}\right)$ in the $a b$ initio emulsion polymerization of MAMs. We attribute their effectiveness to the fact that they are water soluble, or highly surface active in the case of $\mathbf{6}$, and cause little retardation. These and related systems are currently being further explored to establish their full utility in emulsion polymerization. Specifically, there is a need to establish robust and scalable conditions for forming block copolymers and a surfactant regime which additionally provides control over particle shape and size.

\section{Conflicts of interest}

There are no conflicts to declare.

\section{Acknowledgements}

SJS acknowledges CSIRO Manufacturing for a PhD top-up grant. JV acknowledges CSIRO Manufacturing for an Industrial Traineeship. We are grateful to Roger Mulder, Carl Braybrook and Jo Cosgriff for assistance with NMR and mass spectrometry and to Jacinta White for CryoTEM.

\section{Notes and references}


¥ Previous studies ${ }^{47}$ demonstrated that the protonated RAFT agents $\mathbf{4}$ and $\mathbf{8}$ were water soluble and effective in aqueous solution. It was therefore anticipated that these should predominantly localize in the aqueous continuous phase. This expectation was confirmed by experiments where the RAFT agents 4,5 or 8 were partitioned between $\mathrm{D}_{2} \mathrm{O}$ and toluene- $d_{8}$ to show no detectable RAFT agent in the toluene- $d_{8}$ phase by ${ }^{1} \mathrm{H}$ NMR (see Electronic Supplementary Information).

1. J. Chiefari, Y. K. Chong, F. Ercole, J. Krstina, J. Jeffery, T. P. T. Le, R. T. A. Mayadunne, G. F. Meijs, C. L. Moad, G. Moad, E. Rizzardo and S. H. Thang, Macromolecules, 1998, 31, 55595562.

2. A. D. Jenkins, R. I. Jones and G. Moad, Pure Appl. Chem., 2010, 82, 483-491.

3. M. F. Cunningham, Prog. Polym. Sci., 2002, 27, 1039-1067.

4. M. F. Cunningham, Prog. Polym. Sci., 2008, 33, 365-398.

5. P. B. Zetterlund, Y. Kagawa and M. Okubo, Chem. Rev., 2008, 108, 3747-3794.

6. P. B. Zetterlund, S. C. Thickett, S. Perrier, E. Bourgeat-Lami and M. Lansalot, Chem. Rev., 2015, 115, 9745-9800.

7. J. Zhou, H. Yao and J. Ma, Polym. Chem., 2018, 9, 2532-2561.

8. M. Destarac, Polym. Chem., 2018.

9. G. Moad, Polym. Int., 2017, 66, 26-41.

10. D. Charmot, P. Corpart, H. Adam, S. Z. Zard, T. Biadatti and G. Bouhadir, Macromol. Symp., 2000, 150, 23-32.

11. G. Moad, J. Chiefari, J. Krstina, A. Postma, R. T. A. Mayadunne, E. Rizzardo and S. H. Thang, Polym. Int., 2000, 49, 993-1001.

12. T. P. Le, G. Moad, E. Rizzardo and S. H. Thang Polymerization with living characteristics DuPont/CSIRO, WO9801478, 1998

13. P. Corpart, D. Charmot, S. Z. Zard, O. Biadatti and D. Michelet Method for block polymer synthesis by controlled radical polymerization US6153705, 2000

14. J. Krstina, G. Moad, E. Rizzardo, C. L. Winzor, C. T. Berge and M. Fryd, Macromolecules, 1995, 28, 5381-5385.

15. J. Krstina, C. L. Moad, G. Moad, E. Rizzardo, C. T. Berge and M. Fryd, Macromol. Symp., 1996, 111, 13-23.

16. G. Moad, Macromol. Chem. Phys., 2014, 215, 9-26.

17. H. de Brouwer, J. G. Tsavalas, F. J. Schork and M. J. Monteiro, Macromolecules, 2000, 33, 9239-9246.

18. M. J. Monteiro, M. Hodgson and H. De Brouwer, J. Polym. Sci., Part A, Polym. Chem., 2000, 38, 3864-3874.

19. M. J. Monteiro and J. de Barbeyrac, Macromolecules, 2001, 34, 4416-4423.

20. J. B. McLeary, M. P. Tonge, D. de Wet Roos, R. D. Sanderson and B. Klumperman, J. Polym. Sci., Part A, Polym. Chem., 2004, 42, 960-974.

21. M. J. Monteiro, M. Sjöberg, J. van der Vlist and C. M. Göttgens, J. Polym. Sci., Part A, Polym. Chem., 2000, 38, 4206-4217.

22. Y. W. Luo and X. F. Cui, J. Polym. Sci., Part A, Polym. Chem., 2006, 44, 2837-2847.

23. C. N. Urbani, H. N. Nguyen and M. J. Monteiro, Aust. J. Chem., 2006, 59, 728-732.

24. M. Lansalot, T. P. Davis and J. P. A. Heuts, Macromolecules, 2002, 35, 7582-7591.

25. S. W. Prescott, M. J. Ballard, E. Rizzardo and R. G. Gilbert, Macromolecules, 2002, 35, 5417-5425.

26. S. W. Prescott, M. J. Ballard, E. Rizzardo and R. G. Gilbert, Aust. J. Chem., 2002, 55, 415-424.

27. M. Khan, T. R. Guimarães, D. Zhou, G. Moad, S. Perrier and P. B. Zetterlund, J. Polym. Sci., Part A, Polym. Chem., 2019, Ahead of Print.

28. C. J. Ferguson, R. J. Hughes, B. T. T. Pham, B. S. Hawkett, R. G. Gilbert, A. K. Serelis and C. H. Such, Macromolecules, 2002, 35, 9243-9245.
29. C. J. Ferguson, R. J. Hughes, D. Nguyen, B. T. T. Pham, R. G. Gilbert, A. K. Serelis, C. H. Such and B. S. Hawkett, Macromolecules, 2005, 38, 2191-2204.

30. S. Freal-Saison, M. Save, C. Bui, B. Charleux and S. Magnet, Macromolecules, 2006, 39, 8632-8638.

31. T. R. Guimaraes, M. Khan, I. C. Morrow, H. Minami, G. Moad, S. Perrier and P. B. Zetterlund, Macromolecules, 2019, 52, 2965-2974.

32. X. Wang, Y. Luo, B. Li and S. Zhu, Macromolecules, 2009, 42, 6414-6421.

33. J. Fang, K. Yan and Y. Luo, in Reversible Deactivation Radical Polymerization: Materials and Applications, eds. K. Matyjaszewski, H. Gao, B. S. Sumerlin and N. V. Tsarevsky, American Chemical Society, Washington, DC, 2018, pp. 81-106.

34. S. Eggers and V. Abetz, Polymers, 2017, 9, 668.

35. J. Rieger, F. Stoffelbach, C. Bui, D. Alaimo, C. Jerome and B. Charleux, Macromolecules, 2008, 41, 4065-4068.

36. N. P. Truong, M. V. Dussert, M. R. Whittaker, J. F. Quinn and T. P. Davis, Polym. Chem., 2015, 6, 3865-3874.

37. N. P. Truong, J. F. Quinn, A. Anastasaki, M. Rolland, M. N. Vu, D. M. Haddleton, M. R. Whittaker and T. P. Davis, Polym. Chem., 2017, 8, 1353-1363.

38. J. Kim, J. Kwak, Y. Chul Kim and D. Kim, Colloid Polym. Sci., 2006, 284, 771.

39. F. Stoffelbach, L. Tibiletti, J. Rieger and B. Charleux, Macromolecules, 2008, 41, 7850-7856.

40. S. J. Stace, C. M. Fellows, G. Moad and D. J. Keddie, Macromol. Rapid. Commun., 2018, 39, 1800228.

41. A. Tselepy, T. L. Schiller, S. Harrisson, C. Guerrero-Sanchez, G. Moad and D. J. Keddie, Macromolecules, 2018, 51, 410-418.

42. S. J. Stace, G. Moad, C. M. Fellows and D. J. Keddie, Polym. Chem., 2015, 6, 7119-7126.

43. G. Moad, D. Keddie, C. Guerrero-Sanchez, E. Rizzardo and S. H. Thang, Macromol. Symp., 2015, 350, 34-42.

44. D. J. Keddie, C. Guerrero-Sanchez and G. Moad, Polym. Chem., 2013, 4, 3591-3601.

45. D. J. Keddie, C. Guerrero-Sanchez, G. Moad, R. Mulder, E. Rizzardo and S. H. Thang, Macromolecules, 2012, 45, 42054215.

46. G. Moad, M. Benaglia, M. Chen, J. Chiefari, Y. Chong, K., D. Keddie, J., E. Rizzardo and S. H. Thang, in Non-Conventional Functional Block Copolymers, eds. P. Theato, A. F. M. Kilbinger and E. B. Coughlin, American Chemical Society, Columbus, Ohio, 2011, pp. 81-102.

47. D. J. Keddie, C. Guerrero-Sanchez, G. Moad, E. Rizzardo and S. H. Thang, Macromolecules, 2011, 44, 6738-6745.

48. M. Benaglia, J. Chiefari, Y. K. Chong, G. Moad, E. Rizzardo and S. H. Thang, J. Am. Chem. Soc., 2009, 131, 6914-6915.

49. M. Benaglia, M. Chen, Y. K. Chong, G. Moad, E. Rizzardo and S. H. Thang, Macromolecules, 2009, 42, 9384-9386.

50. M. J. Monteiro, M. M. Adamy, B. J. Leeuwen, A. M. van Herk and M. Destarac, Macromolecules, 2005, 38, 1538-1541.

51. E. J. Behrman and J. O. Edwards, Revs. Inorg. Chem., 1980, 2, 179-206.

52. I. M. Kolthoff and I. K. Miller, J. Am. Chem. Soc., 1951, 73, 3055-3059.

53. G. Moad, Prog. Polym. Sci., 2019, 88, 130-188.

54. Y. Zhou, Z. Zhang, A. Postma and G. Moad, Polym. Chem., 2019, 10, 3284-3287.

55. K. Suzuki, Y. Kanematsu, T. Miura, M. Minami, S. Satoh and H. Tobita, Macromol. Theory Simul., 2014, 23, 136-146. 
56. C. P. Jesson, C. M. Pearce, H. Simon, A. Werner, V. J. Cunningham, J. R. Lovett, M. J. Smallridge, N. J. Warren and S. P. Armes, Macromolecules, 2017, 50, 182-191.

57. D. Matioszek, P.-E. Dufils, J. Vinas and M. Destarac, Macromol. Rapid. Commun., 2015, 36, 1354-1361.

58. G. Moad, E. Rizzardo and S. H. Thang, Polym. Int., 2011, 60, 925.

59. J. Chiefari, R. T. A. Mayadunne, C. L. Moad, G. Moad, E. Rizzardo, A. Postma, M. A. Skidmore and S. H. Thang, Macromolecules, 2003, 36, 2273-2283.

60. H. Minami, K. Shimomura, T. Suzuki, K. Sakashita and T. Noda, Macromolecules, 2014, 47, 130-136.

61. M. Yu, J. Tan, J. Yang and Z. Zeng, Polym. Chem., 2016, 7, 37563765.

62. S. Harrisson, X. Liu, J.-N. Ollagnier, O. Coutelier, J.-D. Marty and M. Destarac, Polymers, 2014, 6, 1437-1488.

63. N. Nomura, K. Shinoda, A. Takasu, K. Nagata and K. Inomata, J. Polym. Sci., Part A, Polym. Chem., 2013, 51, 534-545. 